\title{
Recent Developments in Microfluidic Platforms for Immunological Testing
}

\author{
Argus M Sun ${ }^{1 *}$ and John F Wong ${ }^{2}$ \\ ${ }^{1}$ Eidolon Hydros, USA \\ ${ }^{2}$ Moraga Biotechnology, USA \\ *Corresponding author: Argus Sun, PhD, Eidolon Hydros, PO BOX 6154, Buena Park, CA 90622, USA. \\ To Cite This Article: Argus M Sun. Recent Developments in Microfluidic Platforms for Immunological Testing. 2020 - 9(2). AJBSR.MS.ID.001369. \\ DOI: 10.34297/AJBSR.2020.09.001370.
}

Received: 眥June 06, 2020; Published: 筒 June 16, 2020

\begin{abstract}
Microfluidic systems for organoid culture are Lab-on-a-Chip systems that have been pervasive in engineering liver, heart, lung, bone and muscle, but immune organs are somewhat underdeveloped in this field. With the need for new biopharmaceuticals such as immune modulators and vaccines, the need for effective and efficient preclinical testing should increase in parallel. This mini-review seeks to introduce new developments in microfluidic immune models, including thymic microfluidic organoids, and multisensor integration between multiple immune organoid system networks also termed Body-on-a-Chip.
\end{abstract}

\section{Introduction}

Drug and vaccine development is a lengthy and resourceintensive process with significant costs that can be reduced by effective preclinical testing. Microfluidic Organoid or Organ-ona-Chip systems are microfluidic models of tissues and with 3D architecture that allows mimicry of native tissue interactions in organs, with multiple connected organoid systems that can have inline sensors for monitoring and control of flow between chips are termed body-on-a-chip [1-3]. Development of an immunological component of body-on-chip is especially important for testing biopharmaceuticals that can have unpredictable effects such as uncontrolled cytokine release, preventing such leads from entering clinical trials prematurely [4]. Furthermore, a functioning immune system model will allow testing of small molecule drugs, biopharmaceuticals, vaccines as well as evaluate biocompatibility of implanted medical devices, and evaluate tissue interactions preceding organ transplantation. Incorporation of immune organs into circuits with liver-on-chip, heart-on-chip; can accelerate preclinical testing and become substrate for building models for disease pathophysiology. Furthermore, study of immune organson-a-chip generates insight that can make inroads for discovering regenerative therapies for immune deficiencies. Crosstalk between immune organs such as thymus, lymph node and bone marrow in body-on-a-chip systems will produce mimicry of organ-to-organ communication that benefits modeling systems where a complex immunological component is involved [4,5], including drug and device testing and other novel therapeutics where a cascade of immunological events are encountered.

\section{Immune Organs on a Chip}

Current immune testing has evolved rapidly, ranging from in silico prediction of epitopes to proteomic-based binding assays [6]. In cell-based systems, most assays involved coculture in membrane-separated compartments, but some advocate for true 3D architecture organoids [6,7]. Fortunately, the field benefits from the existence of proof-of-concept microfluidic organoid models for lymph node and bone marrow [1,2]. Including thymus gland is important for recapitulating a physiologically realistic model system because of pharmacokinetic volume effects due to the relative sizes of each organ compartment in the chip system [1] and because of thymus effects on $\mathrm{T}$ Cell pool size to accurately recreate in vivo conditions. Thymus can be grown in explant culture using the hanging drop method [8], the first attempt at thymic organoid culture used tantalum-coated carbon matrix scaffolds [9]. Attention has focused on growth and differentiaton of Thymic Epithelial Cells (TEC) because of their role in selection of T Cells $[10,11]$. Existing protocols for 3D organotypic culture of TEC employ a variety of scaffolds including foamed tantalum and recellularized extracellular matrix $[9,12]$. With further development of a $3 \mathrm{D}$ 
immune organoid systems, it will be possible to continue efforts characterizing the mechanical interactions of: TECs and $\mathrm{T}$ Cell precursors; interactions within a TEC layer; interactions between $\mathrm{T}$ Cells and endothelial cells; and interactons between $\mathrm{T}$ Cells encountering antigen-presenting-cells (APCs) $[13,14]$. DNA-probes can enhance the sensitivity of the system by measuring pico newton forces in short-lived interactions as well as characterization of cellsubstrate interactions [15]. Placement of cell-laden scaffolds into specific loci during the layout design of polydimethylsiloxane PDMS microchannels facilitates connection to a Body-on-Chip system $[2,3]$.

\section{Microfluidic Multisensor Monitoring on Immune Body on a Chip}

To characterize and regulate a dynamic body-on-chip system it is important to be able to monitor concentrations of specific biomarkers of interest and chemical conditions in real-time $[3,16]$. With limited effluent from individual organoid systems, multisensor systems capable of detecting multiple analytes become a necessary component of body-on-a-chip systems. The mode of detection for multisensor systems range from electrobiochemical to arrays of cellular biosensors [17-19]. Successful monitoring of complex biological data generated by each organoid system can be aided by machine learning analysis $[17,20,21]$ (Table 1 ) .

\begin{tabular}{|c|c|c|c|}
\hline \multicolumn{1}{|c|}{ Table 1. } & $\begin{array}{c}\text { Cell and/or } \\
\text { Tissue Type }\end{array}$ & $\begin{array}{c}\text { Involved Cytokines, } \\
\text { Growth Factors and } \\
\text { Biomarkers }\end{array}$ & Ref. \\
\hline Thymic Organoid & $\begin{array}{c}\text { TEC, dermal } \\
\text { fibroblast }\end{array}$ & $\begin{array}{c}\text { BMP4, Follistatin, } \\
\text { Activin A }\end{array}$ & {$[8,9,10]$} \\
\hline $\begin{array}{c}\text { Immune Co- } \\
\text { culture }\end{array}$ & PBMC, APC & $\begin{array}{c}\text { CD154, IFN } \gamma, \text { IL-2, } \\
\text { TNF } \alpha \text { CD } 4, \text { IgG/IgM/ } \\
\text { IgA }\end{array}$ & {$[6,7]$} \\
\hline Multisensor & T Cell & TREC & {$[16]$} \\
\hline
\end{tabular}

\section{Conclusion}

The development of Body-on-a-Chip Networks of organoids matures rapidly. The recreation of $3 \mathrm{D}$-architectures in vitro allows for physiologically realistic models for preclinical testing. Generation of preclinical pharmacokinetic and pharmacodynamic data can be accelerated while minimizing the use of animal models Furthermore, these model systems offer potential for increasing basic understanding of the development and formation of the organs comprising the immune system.

\section{Reference}

1. Esch MB, Mahler GJ (2019) Body-on-a-chip systems: Design, fabrication and applications. Elsevier Inc.

2. Sun W, Luo Z, Lee J, Kim HJ, Lee KJ, et al. (2019) Organ-on-a-Chip for Cancer and Immune Organs Modeling Adv Healthc Mater 8: 1-12.

3. Zhang YS, Aleman J, Shin SR, Kilic T, Kim D, et al. (2017) Multisensor-integrated organs-on-chips platform for automated and continual in situ monitoring of organoid behaviors. Proc Natl Acad Sci USA 114 E2293-E2302.
4. Suntharalingam G, Perry MR, Ward S, Brett SJ, Castello Cortes A, et al. (2006) Cytokine Storm in a Phase 1 Trial of the Anti-CD28 Monoclonal Antibody TGN1412. N Engl J Med 355: 1018-1028.

5. Mehta P, McAuley DF, Brown M, Sanchez E, Tattersall RS, et al. (2020) COVID-19: consider cytokine storm syndromes and immunosuppression. Lancet 395: 1033-1034.

6. Duke BR, Mitra Kaushik S. (2019) Current in vitro Assays for Prediction of T Cell Mediated Immunogenicity of Biotherapeutics and Manufacturing Impurities. J Pharm Innov.

7. Dauner A, Agrawal P, Salvatico J, Tapia T, Dhir V,et al. (2017) The in vitro MIMIC® platform reflects age-associated changes in immunological responses after influenza vaccination. Vaccine 35: 5487-5494.

8. Davies JA. (2012) Fetal Organ Culture in Replacing Animal Models: Davies J. Ed. John Wiley \& Sons, Ltd: Chichester.

9. Poznansky MC, Olszak IT, Evans RH, Wang Z, Foxall RB, et al. (2002) Thymocyte emigration is mediated by active movement away from stroma-derived factors. J Clin Invest 109: 1011-1012.

10. Lepletier A, Hun ML, Hammett MV, Wong K, Naeem H, et al. (2019) Interplay between Follistatin, Activin A, and BMP4 Signaling Regulates Postnatal Thymic Epithelial Progenitor Cell Differentiation during Aging. Cell Rep 27: 3887-3901.

11. Kondo K, Ohigashi I, Takahama Y. (2019) Thymus machinery for T-cell selection. Int Immunol. 31: 119-125.

12. Fan Y, Tajima A, Goh SK, Geng X, Gualtierotti G, et al. (2015) Bioengineering thymus organoids to restore thymic function and induce donor-specific immune tolerance to allografts. Mol Ther 23: 1262-1277.

13. Lee HJ, Li N, Siobahn ME, Miguel FD, Wenzel PL. (2014) Biomechanical force in blood development: extrinsic physical cues drive pro-hematopoietic signaling. Bone 23: 1-7.

14. Brockman JM, Salaita K. (2019) Mechanical Proofreading: A General Mechanism to Enhance the Fidelity of Information Transfer Between Cells. Front Phys 7: 139-148.

15. Ma R, Kellner AV, Ma VPY, Su H, Deal BR. et al. (2019) DNA probes that store mechanical information reveal transient piconewton forces applied by T cells. Proc Natl Acad Sci 116: 16949-16954.

16. Al Harthi L, Marchetti G, Steffens CM, Poulin JF, Sékaly RP, et al. (2000) Detection of $\mathrm{T}$ cell receptor circles (TRECs) as biomarkers for de novo $\mathrm{T}$ cell synthesis using a quantitative polymerase chain reaction-enzyme linked immunosorbent assay (PCR-ELISA). J Immunol Methods 237: 187-197.

17. Rodriguez Mendez RL, Apetrei C, Medina Plaza C, Munoz R, Antonio de Saja J (2013) New Developments on Nanostructured and Biomimetic Electrochemical Sensors in Multisensor systems for chemical analysis: Materials and sensors.

18. Campuzano S, Yáñez Sedeño P, Manuel Pingarrón J. (2017) Molecular biosensors for electrochemical detection of infectious pathogens in liquid biopsies: Current trends and challenges. Sensors (Switzerland). p. 17.

19. Roelse M, Henquet MGL, Verhoeven HA, De Ruijter NCA, Wehrens R, et al. (2018) Calcium imaging of GPCR activation using arrays of reverse transfected HEK293 cells in a microfluidic system. Sensors (Switzerland) 18: 1-17.

20. McRae MP, Simmons GW, Wong J, Shadfan B, Gopalkrishnan S, et al. (2015) Programmable bio-nano-chip system: a flexible point-of-care platform for bioscience and clinical measurements. Lab Chip 15: 40204031.

21. Christodoulides N, McRae MP, Simmons GW, Modak SS, McDevitt JT. (2019) Sensors that learn: The evolution from taste fingerprints to patterns of early disease detection. Micromachines p. 10. 